\title{
CYP2D6 phenotype, tamoxifen, and risk of contralateral breast cancer in the WECARE Study
}

Jennifer D. Brooks ${ }^{1 *}$ D, Elizabeth A. Comen ${ }^{2}$, Anne S. Reiner ${ }^{2}$, Irene Orlow² Siok F. Leong ${ }^{2}$, Xiaolin Liang ${ }^{2}$, Lene Mellemkjær ${ }^{3}$, Julia A. Knight ${ }^{1,4}$, Charles F. Lynch ${ }^{5}$, Esther M. John ${ }^{6}$, Leslie Bernstein ${ }^{7}$, Meghan Woods $^{2}$, David R. Doody ${ }^{8}$, The WECARE Study collaborative group, Kathleen E. Malone ${ }^{8+}$ and Jonine L. Bernstein ${ }^{2 \dagger}$

\begin{abstract}
Background: Tamoxifen treatment greatly reduces a woman's risk of developing a second primary breast cancer. There is, however, substantial variability in treatment response, some of which may be attributed to germline genetic variation. CYP2D6 is a key enzyme in the metabolism of tamoxifen to its active metabolites, and variants in this gene have been associated with reduced tamoxifen metabolism. The impact of variation on risk of contralateral breast cancer (CBC) is unknown.

Methods: Germline DNA from 1514 CBC cases and 2203 unilateral breast cancer controls was genotyped for seven single nucleotide polymorphisms, one three-nucleotide insertion-deletion, and a full gene deletion. Each variant has an expected impact on enzyme activity, which in combination allows for the classification of women as extensive, intermediate, and poor metabolizers (EM, IM, and PM respectively). Each woman was assigned one of six possible diplotypes and a corresponding CYP2D6 activity score (AS): EM/EM (AS =2), EM/IM (AS = 1.5), EM/PM (AS = 1), IM/IM $(A S=0.75), I M / P M(A S=0.5)$, and PM/PM $(A S=0)$. We also collapsed categories of the AS to generate an overall phenotype (EM, AS $\geq 1 ; I M, A S=0.5-0.75 ; P M, A S=0$ ). Rate ratios (RRs) and 95\% confidence intervals (Cls) for the association between tamoxifen treatment and risk of CBC in our study population were estimated using conditional logistic regression, stratified by AS.

Results: Among women with $A S \geq 1$ (i.e., EM), tamoxifen treatment was associated with a $20-55 \%$ reduced RR of $C B C(A S=2, R R=-0.81,95 \% \mathrm{Cl} 0.62-1.06 ; A S=1.5, R R=0.45,95 \% \mathrm{Cl} 0.30-0.68$; and $\mathrm{AS}=1, \mathrm{RR}=0.55,95 \% \mathrm{Cl}$ $0.40-0.74$ ). Among women with no EM alleles and at least one PM allele (i.e., IM and PM), tamoxifen did not appear to impact the RR of $C B C$ in this population $(A S=0.5, R R=1.08,95 \% \mathrm{Cl} 0.59-1.96$; and $A S=0, R R=1.17$, $95 \% \mathrm{Cl} 0.58-2.35$ ) ( $p$ for homogeneity $=-0.02$ ).

Conclusion: This study suggests that the CYP2D6 phenotype may contribute to some of the observed variability in the impact of tamoxifen treatment for a first breast cancer on risk of developing CBC.
\end{abstract}

Keywords: Contralateral breast cancer, Tamoxifen, CYP2D6

\footnotetext{
* Correspondence: jennifer.brooks@utoronto.ca

${ }^{\dagger}$ Kathleen E. Malone and Jonine L. Bernstein contributed equally to this work.

${ }^{1}$ University of Toronto, Dalla Lana School of Public Health Sciences, 155

College St. HSB 676, Toronto, ON M5T 3M7, Canada

Full list of author information is available at the end of the article
}

(c) The Author(s). 2018 Open Access This article is distributed under the terms of the Creative Commons Attribution 4.0 International License (http://creativecommons.org/licenses/by/4.0/), which permits unrestricted use, distribution, and reproduction in any medium, provided you give appropriate credit to the original author(s) and the source, provide a link to the Creative Commons license, and indicate if changes were made. The Creative Commons Public Domain Dedication waiver (http://creativecommons.org/publicdomain/zero/1.0/) applies to the data made available in this article, unless otherwise stated. 


\section{Introduction}

The high incidence of breast cancer in the United States, coupled with a high rate of survival, places an increasing number of women at risk of contralateral breast cancer (CBC) [1] . CBC is the most common malignancy among breast cancer survivors, accounting for nearly $40 \%$ of all second cancers [2]. Tamoxifen treatment for a first primary breast cancer greatly reduces a woman's risk of developing $\mathrm{CBC}$ [3-6]. However, there is substantial variability in treatment response, some of which may be attributed to germline genetic variation in drug metabolism.

CYP2D6 is a key enzyme in tamoxifen metabolism and has been central to the pharmacogenetic investigation of tamoxifen treatment response. Focus has been placed on CYP2D6 because it is responsible for the metabolism of tamoxifen to its two primary active metabolites, 4hydroxytamoxifen and endoxifen. Compared to tamoxifen, these metabolites have over 100-fold higher affinity for the estrogen receptor (ER), and 30 -fold to 100 -fold greater potency in suppressing estrogen-dependent tumor cell growth $[7,8]$. Carriers of certain variants in CYP2D6 have been shown to have reduced enzyme activity and lower circulating levels of active metabolites [9].

Given these effects on tamoxifen metabolism, studies have examined the impact of variation in CYP2D6 on breast cancer recurrence and mortality, with mixed results [10-27]. These studies have not addressed the impact of variation in CYP2D6 on risk of CBC. It is currently unknown whether germline variation in CYP2D6 modifies the association between tamoxifen treatment and risk of $\mathrm{CBC}$. Given the relationship between tamoxifen and risk of $\mathrm{CBC}$, this is potentially a critical clinical issue. The objective of this study was to examine the impact of genetically inferred CYP2D6 phenotype on the association between tamoxifen treatment for a first breast cancer and the risk of $\mathrm{CBC}$ in a large population-based case-control study.

\section{Materials and methods Study population}

The Women's Environmental Cancer and Radiation Epidemiology (WECARE) Study is a multicenter, populationbased case-control study where cases are women with asynchronous $\mathrm{CBC}$ and controls are women with unilateral breast cancer (UBC). Case-control recruitment for the WECARE Study was conducted in two phases: WECARE I (2001-2004) and WECARE II (2009-2012). Participants were identified through eight population-based cancer registries: Los Angeles County Cancer Surveillance Program; Cancer Surveillance System of the Fred Hutchinson Cancer Research Center (Seattle, WA, USA); State Health Registry of Iowa; The Cancer Surveillance Program of Orange County/San Diego-Imperial Organization for Cancer Control (Orange County/San Diego, CA, USA); the Greater
Bay Area Cancer Registry (San Francisco Bay Area Region and Santa Clara Region, CA, USA); and the Sacramento and Sierra Center Registries (Sacramento Region, CA, USA). These cancer registries all contribute to the National Cancer Institute (NCI) Surveillance, Epidemiology and End Results (SEER) program in the United States. Patients were also recruited from the Ontario (Canada) Cancer Registry and the Danish Breast Cancer Cooperative Group Registry, supplemented by data from the Danish Cancer Registry. All study participants provided written informed consent, and the study protocol was reviewed and approved by the Institutional Review Board at each recruitment site and the ethical committee systems in Denmark and Ontario. Across the eight cancer registries a total of 2354 CBC cases and 3599 UBC controls were identified as being eligible and were approached for the study. The final number of participants who completed the interview and provided a biospecimen for DNA analysis was 1518 (64\%) cases and 2208 (61\%) controls. Reasons for nonparticipation have been described in detail [28]. An additional nine participants were excluded from the current analysis due to low quality or quantity of DNA (four cases, five controls), resulting in a final sample size of 1514 CBC cases and 2203 UBC controls.

Details of recruitment procedures, eligibility, and the study questionnaire have been described previously, and were nearly identical for the two study phases [29]. Briefly, all women were diagnosed prior to age 55 years between 1985 and 2010 with a first primary invasive breast cancer (stage I-III). Cases were diagnosed with a second primary CBC (in situ or invasive for WECARE I and invasive only for WECARE II) at least 1 year later. Controls also had no history of any second cancer diagnosis up to their reference date. The reference date for cases was the $\mathrm{CBC}$ diagnosis date, while for controls this was defined by adding the interval between the first breast cancer and the $\mathrm{CBC}$ for the matched case to the date of (first) breast cancer diagnosis for the control. Cases must also have been living in the same study reporting area for both diagnoses, while controls were required to be living in the cancer-reporting area of their (first) breast cancer diagnoses on their reference dates. Additionally, controls must not have undergone prophylactic mastectomy of the unaffected contralateral breast. Study eligibility was restricted to women who were alive when contacted and were able to provide informed consent, complete a telephone interview, and donate a blood or saliva sample for DNA extraction. Controls were matched to cases (2:1 for WECARE I and 1:1 for WECARE II) on year of birth in 5-year strata, year of diagnosis in 4-year strata, cancer registry region, and race/ethnicity. In WECARE I, cases and controls were further counter-matched based on cancer registry-reported radiation treatment such that two members of each case-control trio had received 
radiation treatment for their first breast cancer and the other member had not [29]. Counter-matching was not used in WECARE II; this was taken into account in all statistical analyses, as detailed in the following. The selection of case-control trios in this way for WECARE I is reflected in the frequency of radiation treatment by casecontrol status such that the frequencies cannot be directly compared. For this reason, weighted frequencies are provided (Table 1).

\section{Data collection}

WECARE Study participants were interviewed by telephone using a structured questionnaire that was designed to obtain information about events occurring before the diagnosis of the first primary breast cancer, as well as events that occurred during the at-risk period. The at-risk period was defined as beginning at least 1 year after diagnosis with a first breast cancer and ending at the second diagnosis in $\mathrm{CBC}$ cases, or the corresponding reference date for UBC controls. The study questionnaire included questions about personal demographics, medical history, family and reproductive history, hormone use, body size, smoking status, and alcohol intake. Additionally, medical records, pathology reports, and hospital charts were used to collect detailed treatment information (i.e., chemotherapy, hormonal therapy, and radiation therapy) for the first primary breast cancer, any recurrences experienced prior to the reference date, and tumor characteristics of the first primary tumor (e.g., ER status, histology).

\section{Genotyping}

Germline DNA was isolated from blood using standard phenol-chloroform extraction methods or from saliva using the manufacturer's recommendations (Genotek, ON, Canada). Samples were genotyped for seven single nucleotide polymorphisms (SNPs), one three-nucleotide insertion-deletion (indel), and a full gene deletion (Table 2), accounting for most of the clinically significant variants in CYP2D6 [30]. Genotyping was conducted in the Molecular Epidemiology Laboratory at Memorial Sloan Kettering Cancer Center using PCR-based methods.

Variants were tested using Agena iPlex chemistry and the MassArray system (Agena Bioscience, San Diego CA, USA), with assays designed using the Agena $\mathrm{Cx}$ online tools (currently https://agenacx.com), and a method similar to that reported by Falzoi et al. [31], with an independent preamplification of CYP2D6 in a long-range PCR. The PCR products were verified on a $1 \%$ agarose gel. One microliter of the amplified product was used for genotyping using specific primers and cycling conditions (Additional file 1). Products were purified enzymatically, extended and desalted, and then spotted onto 384 SpectroCHIP bioarrays (Agena Bioscience). Cluster plots were evaluated with the TyperAnalyzer application
(MassARRAY v3.4). Assays were considered optimal according to degree of clustering, absence of signal in the blanks, and reproducibility. Quality control (QC) procedures were similar to those published elsewhere [32, 33], and included 5\% intraplate duplicates for each plate, $0.5 \%$ interplate duplicates, and at least two independent readers for review and interpretation of cluster plots and results. Samples with known genotypes from the Coriell Institute were also included as controls during the assay development. Samples with weak signals were repeated.

Full CYP2D6 deletion (CYP2D6*5) analysis was conducted with a modified three-primer-based, long-range PCR using primers described by Okubo et al. [34] to ensure gene specificity. Genomic DNA (30 ng) was amplified in a reaction mix containing $1 \times$ Takara LA-Taq PCR buffer with $2.5 \mathrm{mM} \mathrm{Mg}^{2+}$ (Clontech, Mountain View, CA, USA), $0.5 \mathrm{mM}$ dNTPs (Life Technologies, Carlsbad, CA, USA), $0.5 \mu \mathrm{M}$ of each primer, and 0.4 units of Takara LA Taq DNA Polymerase (Clontech), in a total volume of $8 \mu \mathrm{l}$. Cycling included denaturation at $94^{\circ} \mathrm{C}$ for $1 \mathrm{~min}$, 25 cycles of $98^{\circ} \mathrm{C}$ for $20 \mathrm{~s}$ and $70^{\circ} \mathrm{C}$ for $6 \mathrm{~min}$, annealing at $70^{\circ} \mathrm{C}$ for $6 \mathrm{~min}$, and a final hold at $4{ }^{\circ} \mathrm{C}$. PCR products were run on 1\% e-gels (Invitrogen, Carlsbad, CA, USA), and band sizes were determined against molecular weight markers to evaluate CYP2D6 presence (4.7 kb band) or deletion (CYP2D6*5, $3.5 \mathrm{~kb})$. QC procedures included use of control samples from the Coriell Institute, $5 \%$ intraplate and $0.5 \%$ interplate duplicates, as well as negative (sterile distilled water) controls.

\section{CYP2D6 activity score and phenotype assignment}

CYP2D6 nomenclature came from the American College of Medical Genetics and Genomes (ACMG) Standards and Guidelines [35] and PharmVar (Pharmacogene Variation Database, www.Pharmvar.org/gene/CYP2D6 (Table 1). Alleles were classified into three categories based on their anticipated impact on CYP2D6 activity (normal, CYP2D6"1 and $C Y P 2 D 6 * 2$; reduced, CYP2D6*9, CYP2D6*10, and CYP2D6*41; and inactive, CYP2D6*3, CYP2D6*4, CYP2D6*5, and CYP2D6*6) [9] and assigned activity scores (AS) of $1,0.5$, and 0 , respectively. The scores for the two alleles carried by each woman were summed in order to assign an overall AS which could range from 0 to 2 . One exception to this is the instance of individuals carrying two IM (reduced activity) alleles. In order to distinguish between two combinations that would otherwise have had the same overall AS of 1.0, we left individuals classified as EM/ $\mathrm{PM}$ with an AS of 1 and assigned IM/IM women an AS of 0.75 (instead of the AS of 1.0 they would otherwise have received) [26]. In this way, women were classified as: EM/ $\mathrm{EM}(\mathrm{AS}=2), \mathrm{EM} / \mathrm{IM}(\mathrm{AS}=1.5), \mathrm{EM} / \mathrm{PM}(\mathrm{AS}=1), \mathrm{IM} / \mathrm{IM}$ $(\mathrm{AS}=0.75), \mathrm{IM} / \mathrm{PM}(\mathrm{AS}=0.5)$, and $\mathrm{PM} / \mathrm{PM}(\mathrm{AS}=0)[26$, 36, 37]. Analyses were also conducted collapsing across some categories of the AS to generate an overall 
Table 1 Characteristics of CBC cases and UBC controls and those treated and not treated with tamoxifen from the WECARE Study population who were also screened for CYP2D6 variants

\begin{tabular}{|c|c|c|c|c|}
\hline Variable & $\begin{array}{l}\text { CBC cases } \\
(N=1514)\end{array}$ & $\begin{array}{l}\text { UBC controls } \\
(N=2203)\end{array}$ & $\begin{array}{l}\text { Tamoxifen treatment } \\
(N=1250)\end{array}$ & $\begin{array}{l}\text { No tamoxifen } \\
\text { treatment }(N=2467)\end{array}$ \\
\hline Age at first diagnosis (years), median (range) & $46(24-54)$ & $48(24-54)$ & $48(24-54)$ & $45(23-54)$ \\
\hline Age at reference date (years), median (range) & $53(27-73)$ & $54(28-73)$ & $54(28-73)$ & $51(27-71)$ \\
\hline Length of at-risk period (years) ${ }^{\mathrm{a}}$, median (range) & $6.3(1.0-19.8)$ & $6.0(1.0-19.3)$ & $6.0(1.0-19.3)$ & $5.8(1.0-19.8)$ \\
\hline \multicolumn{5}{|l|}{ Study area, N (\%) } \\
\hline lowa & $201(13)$ & $314(14)$ & $170(14)$ & $345(14)$ \\
\hline California $^{c}$ & $655(43)$ & $963(44)$ & $634(51)$ & $984(40)$ \\
\hline Seattle $^{d}$ & $223(15)$ & $317(14)$ & $249(20)$ & $291(12)$ \\
\hline Denmark $^{\mathrm{e}}$ & $279(18)$ & $452(21)$ & $57(5)$ & $674(27)$ \\
\hline Canada $^{f}$ & $156(10)$ & $157(7)$ & $140(11)$ & $173(7)$ \\
\hline \multicolumn{5}{|l|}{ Year of first breast cancer diagnosis, $N(\%)$} \\
\hline 1985-1988 & $238(16)$ & $466(21)$ & $122(10)$ & $582(24)$ \\
\hline 1989-1992 & $414(27)$ & $643(29)$ & $328(26)$ & $729(30)$ \\
\hline 1993-1996 & $425(28)$ & $630(29)$ & $353(28)$ & $702(28)$ \\
\hline 1997-2008 & $437(29)$ & $464(21)$ & $447(36)$ & $454(18)$ \\
\hline \multicolumn{5}{|l|}{ Race/ethnicity ${ }^{9}, N(\%)$} \\
\hline Non-Hispanic white & $1330(88)$ & $1971(89)$ & $1070(86)$ & $2231(90)$ \\
\hline Hispanic white & $68(4)$ & $93(4)$ & $59(5)$ & $102(4)$ \\
\hline Black & $54(4)$ & $75(3)$ & $47(4)$ & $82(3)$ \\
\hline Asian & $45(3)$ & $52(2)$ & $61(5)$ & $36(1)$ \\
\hline Other & $17(1)$ & $12(1)$ & $13(1)$ & $16(1)$ \\
\hline \multicolumn{5}{|l|}{ Age at menarche (years), $N(\%)$} \\
\hline Never had menses & $3(0)$ & $6(0)$ & $1(0)$ & $8(0)$ \\
\hline$<13$ & $722(48)$ & $962(44)$ & $622(50)$ & $1062(43)$ \\
\hline$\geq 13$ & $786(52)$ & $1233(56)$ & $625(50)$ & $1394(57)$ \\
\hline Unknown & $3(0)$ & $2(0)$ & $2(0)$ & $3(0)$ \\
\hline \multicolumn{5}{|l|}{ Number of full-term pregnancies, $N(\%)$} \\
\hline None & $320(21)$ & $408(19)$ & $246(20)$ & $482(20)$ \\
\hline 1 & $271(18)$ & $340(15)$ & $200(16)$ & $411(17)$ \\
\hline 2 & $556(37)$ & $839(38)$ & $444(36)$ & $951(39)$ \\
\hline 3 & $255(17)$ & $386(18)$ & $237(19)$ & $404(16)$ \\
\hline$\geq 4$ & $107(7)$ & $225(10)$ & $118(9)$ & $214(9)$ \\
\hline Unknown & $5(0)$ & $5(0)$ & $5(0)$ & $5(0)$ \\
\hline \multicolumn{5}{|l|}{ Menopausal status at first diagnosis ${ }^{h}, N(\%)$} \\
\hline Premenopausal & $1119(74)$ & $1669(76)$ & $865(69)$ & $1923(78)$ \\
\hline Postmenopausal & $387(26)$ & $520(24)$ & $377(30)$ & $530(21)$ \\
\hline Unknown & $8(1)$ & $14(1)$ & $8(1)$ & $14(1)$ \\
\hline \multicolumn{5}{|l|}{ First-degree family history of breast cancer, N (\%) } \\
\hline No & $999(66)$ & $1697(77)$ & $901(72)$ & $1795(73)$ \\
\hline Yes & $496(33)$ & $466(21)$ & $325(26)$ & $637(26)$ \\
\hline Adopted/unknown & $19(1)$ & $40(2)$ & $24(2)$ & $35(1)$ \\
\hline
\end{tabular}


Table 1 Characteristics of CBC cases and UBC controls and those treated and not treated with tamoxifen from the WECARE Study population who were also screened for CYP2D6 variants (Continued)

\begin{tabular}{|c|c|c|c|c|}
\hline Variable & $\begin{array}{l}\text { CBC cases } \\
(N=1514) \\
\end{array}$ & $\begin{array}{l}\text { UBC controls } \\
(N=2203)\end{array}$ & $\begin{array}{l}\text { Tamoxifen treatment } \\
(N=1250)\end{array}$ & $\begin{array}{l}\text { No tamoxifen } \\
\text { treatment }(N=2467)\end{array}$ \\
\hline \multicolumn{5}{|c|}{ Stage of first primary breast cancer, $N(\%)$} \\
\hline Local & $1059(70)$ & $1436(65)$ & $747(60)$ & $1748(71)$ \\
\hline Regional & $446(29)$ & $756(34)$ & $493(39)$ & 709 (29) \\
\hline Unknown & $9(1)$ & $11(1)$ & $10(1)$ & $10(0)$ \\
\hline \multicolumn{5}{|l|}{ Histology of first diagnosis, $N(\%)$} \\
\hline Nonlobular & $1334(88)$ & $1978(90)$ & $1061(85)$ & $2251(91)$ \\
\hline Lobular & $179(12)$ & $222(10)$ & $186(15)$ & $215(9)$ \\
\hline Unknown & $1(0)$ & $3(0)$ & $3(0)$ & $1(0)$ \\
\hline \multicolumn{5}{|l|}{ ER status of first diagnosis, $N(\%)$} \\
\hline Positive & $793(52)$ & $1248(57)$ & $1047(84)$ & $994(40)$ \\
\hline Negative & $467(31)$ & $560(25)$ & $129(10)$ & $898(36)$ \\
\hline Other/unknown & $254(17)$ & $395(18)$ & $74(6)$ & $575(23)$ \\
\hline \multicolumn{5}{|c|}{ Chemotherapy for first diagnosis, $N(\%)$} \\
\hline No & $696(46)$ & $919(42)$ & $485(39)$ & $1130(46)$ \\
\hline Yes & $818(54)$ & $1284(58)$ & $765(61)$ & $1337(54)$ \\
\hline \multicolumn{5}{|c|}{ Radiation treatment for first diagnosis,,$N(\%)$} \\
\hline \multicolumn{5}{|l|}{ WECARE I } \\
\hline No & $362(51)$ & $265(50)$ & $139(25)$ & $488(32)$ \\
\hline Yes & $346(49)$ & $1130(50)$ & $424(75)$ & $1052(68)$ \\
\hline Unknown & $0(0)$ & $0(0)$ & $0(0)$ & $0(0)$ \\
\hline \multicolumn{5}{|l|}{ WECARE ॥ } \\
\hline No & $275(34)$ & $258(32)$ & $195(28)$ & $338(36)$ \\
\hline Yes & $531(66)$ & $549(68)$ & $491(71)$ & $589(64)$ \\
\hline Unknown & $0(0)$ & $1(0)$ & $1(0)$ & $0(0)$ \\
\hline \multicolumn{5}{|c|}{ Hormone treatment for first diagnosis, $N(\%)$} \\
\hline None & $960(63)$ & $1263(57)$ & NA & NA \\
\hline Tamoxifen & $465(31)$ & $785(36)$ & & \\
\hline Other hormonal treatment ${ }^{k}$ & $89(6)$ & $153(7)$ & & \\
\hline Unknown & $0(0)$ & $2(0)$ & & \\
\hline
\end{tabular}

$C B C$ contralateral breast cancer, UBC unilateral breast cancer, WECARE Women's Environmental Cancer and Radiation Epidemiology, ER estrogen receptor, NA not available

${ }^{a}$ Beginning at least 1 year after first diagnosis and extending to the date of $\mathrm{CBC}$ diagnosis of cases

${ }^{\mathrm{b}}$ The State Health Registry of lowa

${ }^{\mathrm{C}}$ Four study centers: Los Angeles County Cancer Surveillance Program; The Cancer Surveillance Program of Orange County/San Diego-Imperial Organization for

Cancer Control; Greater Bay Area Cancer Registry (San Francisco Bay Area Region and Santa Clara Region); and Sacramento and Sierra Center Registries

(Sacramento Region)

${ }^{\mathrm{d} C a n c e r}$ Surveillance System of the Fred Hutchinson Cancer Research Center

'The Danish Breast Cancer Cooperative Group Database supplemented by the Danish Cancer Registry

${ }^{\mathrm{f}}$ The Ontario Cancer Registry

g'Asian' includes Japanese, Chinese, and Filipino; 'Other' includes other Asian as well as all other races/ethnicities

${ }^{h}$ Women were classified as premenopausal if they reported having menstrual periods or being pregnant within 2 years of initial diagnosis

"Other/unknown' category consists of women where no laboratory test was given, the test was given and the results are unknown, or the test was given and the results were borderline; estimates not reported. Start date for ER reporting in Surveillance Epidemiology and End Results was January 1, 1990

jProportion of individuals treated and not treated with radiation. In WECARE 1, cases and controls were counter-matched based on cancer registry reported radiation treatment such that two members of each case-control trio had received radiation treatment for their first breast cancer diagnosis. Proportions for controls in WECARE 1 are weighted to reflect this selection. Proportions for cases in WECARE 1 (because all cases were included) and both cases and controls in WECARE II (because counter-matching was not used in WECARE II) are not weighted

kOther hormonal therapies include: raloxifene/Evista, tormifene/Fareston, anastrozole/Arimidex, letrozole/Femara, aromasin/Exemestane, aminoglutethimide/ Cytradren, gosereline/Zoladex, leuprolide/Lupron, faslodex/Fulvestrant, and megestrol acetate/Megace 
Table 2 Summary of genotyped CYP2D6 variants and associated phenotype

\begin{tabular}{|c|c|c|c|c|c|}
\hline Allele & SNP (RefSeq) $)^{a}$ & Variant & CYP2D6 activity & Activity score value $^{\mathrm{b}}$ & Phenotype \\
\hline$\overline{C Y P 2 D 6 * 1}$ & NA & Wild type & Normal & 1 & EM \\
\hline CYP2D6*2 & rs16947, rs1135840 & $2850 \mathrm{C}>\mathrm{T}, 4180 \mathrm{G}>\mathrm{C}$ & Normal & 1 & EM \\
\hline CYP2D6*3 & rs35742686 & 2549delA & Inactive & 0 & EM \\
\hline CYP2D6*4 & rs3892097 & $1846 \mathrm{G}>\mathrm{A}$ & Inactive & 0 & PM \\
\hline CYP2D6*5 & NA & Full gene deletion & Inactive & 0 & PM \\
\hline CYP2D6*6 & rs5030655 & 1707delT & Inactive & 0 & PM \\
\hline CYP2D6*9 & rs5030656 & 2615_2617del AAG & Reduced & 0.5 & IM \\
\hline CYP2D6*10 & rs1065852, rs1135840 & $100 C>T, 4180 G>C$ & Reduced & 0.5 & IM \\
\hline CYP2D6*41 & rs28371725 & $2988 G>A$ & Reduced & 0.5 & IM \\
\hline
\end{tabular}

$S N P$ single nucleotide polymorphism, RefSeq reference sequence, $N A$ not applicable, $E M$ extensive metabolizer, $P M$ poor metabolizer, $I M$ intermediate metabolizer ${ }^{a}$ Where more than one SNP is listed for a given allele, a variant at only one loci needed to be present to classify an individual as having that allele

${ }^{b}$ Activity score (AS) calculated as the sum of the activity score value for each allele held by an individual for a range of values from 0 to 2 . One exception to this is the instance of individuals carrying two IM (reduced activity) alleles, where we provided a distinction between individuals classified as EM/PM (AS $=1)$, IM/IM $(A S=0.75)$, and IM/PM (AS = 0.5)

inferred phenotype. Women were classified as EM if they had at least one EM allele (i.e., AS $\geq 1$ ), IM if they had no EM alleles and at least one IM allele (e.g., AS $=0.5-0.75$ ), or PM if they had two PM alleles (i.e., AS =0) [27].

\section{Statistical analysis}

Rate ratios (RRs) and 95\% confidence intervals (CIs) for the association between tamoxifen treatment and risk of $\mathrm{CBC}$ in our study population were estimated fitting conditional logistic regression models, stratified by CYP2D6 AS. Rate ratios can be interpreted as a relative risk (e.g., ratio of risks) of $\mathrm{CBC}$ in tamoxifen-treated versus untreated women in our study population. Models were adjusted for: age at first diagnosis, histology, stage, and ER status of first diagnosis, first-degree family history of breast cancer, chemotherapy for first breast cancer, radiation treatment for first breast cancer, hormonal therapy other than tamoxifen for a first breast cancer, number of full-term pregnancies before first diagnosis, and age at menarche. Because treatment for a first breast cancer could induce menopause, menopausal status and age at menopause 2 years prior to first diagnosis were used. To account for the counter-matching in WECARE I, we included a log-weight covariate offset term. For WECARE II participants who were matched in pairs (without counter-matching on radiation treatment), we assigned the value of 1 to be the offset term. We used the likelihood ratio test to test for homogeneity of treatment effect across AS/phenotypes. A sensitivity analysis was conducted restricting model fitting to Caucasian women $(N=1335$ CBC cases and $N=1980$ UBC controls) to address the issue of ancestral differences in genotype frequencies. All statistical analyses were conducted using SAS 9.4 (SAS Institute Inc., Cary, NC, USA).

\section{Results}

Table 1 presents the characteristics of the women included in this analysis. The median age at diagnosis for both cases and controls was 46 years, and the majority of women were premenopausal at the time of first breast cancer diagnosis ( $74 \%$ of cases and $76 \%$ of controls). Just over half of all first breast cancers in cases (52\%) and controls (57\%) were ER-positive. Of the 793 cases with an ER-positive first primary breast cancer, 389 (49.1\%) received tamoxifen. A slightly higher proportion of controls with an ER-positive breast cancer was treated with tamoxifen (53\%). An additional 57 cases and 97 controls with an ER-positive first breast cancer were treated with hormonal medications other than tamoxifen (e.g., raloxifene, aromatase inhibitors). This left 839 (347 cases and 492 controls) women with an ER-positive first breast cancer who did not receive any hormonal treatment. Notably, 45 (9.6\%) and 84 (15\%) ER-negative cases and controls, and $31(12.2 \%)$ and $43(10.9 \%)$ cases and controls with unknown ER status, also received tamoxifen.

All minor allele frequencies (MAFs) were comparable to the expected frequencies in a predominantly Caucasian study population (Additional file 2). Genotyping call rates were high and ranged from 99.0 to $99.9 \%$ with intraplate and interplate concordance of $95 \%$ or greater. Although some variants were found to deviate from Hardy-Weinberg equilibrium (HWE), these results may not be meaningful given the absence of an unaffected control group.

First, we examined the effect of tamoxifen treatment for a first primary breast cancer on the risk of $\mathrm{CBC}$, according to the individual CYP2D6 AS levels. Among women with AS $\geq 1$, those treated with tamoxifen for a first primary breast cancer had a $20-55 \%$ lower risk of $\mathrm{CBC}$ ( $\mathrm{AS}=2$, $\mathrm{RR}=0.81,95 \%$ CI $0.62-1.06 ; \mathrm{AS}=1.5, \mathrm{RR}=0.45,95 \% \mathrm{CI}$ $0.30-0.68$; and $\mathrm{AS}=1, \mathrm{RR}=0.55,95 \%$ CI $0.40-0.74$ ) relative to those not treated with tamoxifen (Table 3). Among 
Table 3 Association between tamoxifen treatment and risk of CBC stratified by CYP2D6 activity score in the WECARE Study population $^{a}$

\begin{tabular}{|c|c|c|c|c|c|c|c|}
\hline \multirow[t]{2}{*}{ Activity score ${ }^{b}$} & \multicolumn{3}{|c|}{ No tamoxifen treatment } & \multicolumn{4}{|c|}{ Tamoxifen treatment } \\
\hline & $\begin{array}{l}\text { Cases } \\
N(\%)\end{array}$ & $\begin{array}{l}\text { Controls } \\
N(\%)\end{array}$ & $\begin{array}{l}\text { RR } \\
(95 \% \mathrm{Cl})\end{array}$ & $\begin{array}{l}\text { Cases } \\
N(\%)\end{array}$ & $\begin{array}{l}\text { Controls } \\
N(\%)\end{array}$ & $\begin{array}{l}R^{c} \\
(95 \% \mathrm{Cl})\end{array}$ & $p^{d}$ \\
\hline 2 & 395 (38) & 549 (39) & Reference & $193(42)$ & $300(38)$ & $0.81(0.62-1.06)$ & 0.02 \\
\hline 1.5 & $192(18)$ & $205(14)$ & Reference & $65(14)$ & $141(18)$ & $0.45(0.30-0.68)$ & \\
\hline 1 & $317(30)$ & $436(31)$ & Reference & $128(28)$ & $235(30)$ & $0.55(0.40-0.74)$ & \\
\hline 0.75 & $30(3)$ & $32(2)$ & Reference & $20(4)$ & $23(3)$ & $0.64(0.26-1.58)$ & \\
\hline 0.5 & $58(6)$ & $98(7)$ & Reference & $38(8)$ & $54(7)$ & $1.08(0.59-1.96)$ & \\
\hline 0 & $57(5)$ & $98(7)$ & Reference & $21(5)$ & $32(4)$ & $1.17(0.58-2.35)$ & \\
\hline \multicolumn{8}{|l|}{ Phenotype $^{e}$} \\
\hline EM & $904(86)$ & $1190(84)$ & Reference & $386(83)$ & $676(86)$ & $0.63(0.51-0.78)$ & 0.09 \\
\hline IM & $88(8)$ & $130(9)$ & Reference & $58(12)$ & $77(10)$ & $0.95(0.57-1.56)$ & \\
\hline PM & $57(5)$ & $98(7)$ & Reference & $21(5)$ & $32(4)$ & $1.18(0.59-2.37)$ & \\
\hline
\end{tabular}

$C B C$ contralateral breast cancer, WECARE Women's Environmental Cancer and Radiation Epidemiology, $R R$ rate ratio, $C l$ confidence interval, $E M$ extensive metabolizer, $I M$ intermediate metabolizer, $P M$ poor metabolizer

${ }^{a}$ Analysis includes 1514 CBC cases and 2203 unilateral breast cancer controls

${ }^{\mathrm{b}}$ Activity score (AS) is derived from diploid phenotypes: PM/PM (AS =0), PM/IM (AS = 0.5), IM/IM (AS = 0.75), PM/EM (AS = 1), IM/EM (AS = 1.5), and EM/EM (AS = 2)

${ }^{c}$ Adjusted for: age at first primary, age at menopause 2 years prior to first primary cancer, histology of first primary cancer, stage of first primary cancer, family history of breast cancer, chemotherapy at first primary cancer, radiation at first primary cancer, other hormonal therapy at first primary cancer, number of full-term pregnancies at first primary cancer, age at menarche, estrogen receptor status of first breast cancer diagnosis, and an offset term to take into account the counter-matching for radiation treatment used in WECARE I

${ }^{\mathrm{d}} p$ value for the test that all RRs are equal across AS/phenotype categories ( $p$ for homogeneity)

'Phenotype defined as: EM, having at least one EM allele (i.e., $A S \geq 1$ ); IM, having no EM alleles and at least one IM allele (i.e., $A S=0.5-0.75$ ); and PM, having two PM alleles (i.e., $\mathrm{AS}=0$ )

individuals with no EM alleles and at least one PM allele, tamoxifen use was not associated with a reduction in the risk of $\mathrm{CBC}(\mathrm{AS}=0.5, \mathrm{RR}=1.08,95 \% \mathrm{CI} 0.59-1.96$; and $\mathrm{AS}=0, \mathrm{RR}=1.17,95 \% \mathrm{CI} 0.58-2.35$ ) ( $p$ for homogeneity $=0.02$ ). When AS categories were grouped to classify individuals based on overall phenotype (EM, AS $\geq 1$; IM, $\mathrm{AS}=0.5$ or 0.75 ; $\mathrm{PM}, \mathrm{AS}=0$ ), women with at least one fully functional (EM) allele (i.e., AS $\geq 1$ ) treated with tamoxifen had nearly a $40 \%$ lower risk of CBC relative to those not treated with tamoxifen $(\mathrm{RR}=0.63$, 95\% CI 0.510.78). Conversely, women classified as IM or PM (i.e., AS < 1) treated with tamoxifen were not at a lower risk of $\mathrm{CBC}(\mathrm{RR}=0.95,95 \% \mathrm{CI} 0.57-1.56$ and $\mathrm{RR}=1.18$, 95\% CI 0.59-2.37, respectively). However, these results (by AS phenotype) were not statistically significantly different ( $p$ for homogeneity of 0.09). Restricting the analyses to women with an ER-positive first primary breast cancer, to women who were premenopausal at first diagnosis, or to Caucasian women did not alter the results (Additional files 3, 4, and 5).

\section{Discussion}

Prior studies have examined the association between CYP2D6 phenotype and breast cancer recurrence, recurrence-free survival, and breast cancer-specific and overall survival, with mixed results. A recent meta-analysis found a small but statistically significant increase in tumor recurrence in women who were classified as poor metabolizers ( $\mathrm{HR}=1.25$, 95\% CI 1.06-1.47) [38], although results were variable (and not statistically significant) when criteria for study inclusion were modified to include additional studies. The mixed findings of these prior studies [21-25] suggest that, although CYP2D6 variation has been shown to influence tamoxifen metabolism, the impact of this variation on recurrence and survival is likely null or small $[9,27]$. Indeed, current recommendations do not support routine genotyping of CYP2D6 to guide tamoxifen treatment decisions [39]. The current study, however, is the first to address the impact of this genetic variation on risk of $\mathrm{CBC}$ following tamoxifen treatment for the first primary breast cancer.

The results of this study suggest that the CYP2D6 phenotype could modify the association between tamoxifen treatment for a first primary breast cancer and risk of $\mathrm{CBC}$. While women with CYP2D6 AS $\geq 1$ (i.e., EM) who were treated with tamoxifen had a lower risk of $\mathrm{CBC}$ relative to those not treated with tamoxifen (RR $=0.63$, 95\% CI 0.51-0.78), women classified as having AS < 1 (i.e., IM or PM) who were treated with tamoxifen were not at lower risk of $\mathrm{CBC}(\mathrm{RR}=0.95,95 \% \mathrm{CI}$ $0.57-1.56$ and $R R=1.18,95 \%$ CI 0.59-2.37, respectively). Although these results are not statistically significantly different ( $p$ for homogeneity $=0.09$ ), the overall trend appeared to be consistent. The exception is 
the finding for EM/EM (AS=2), where $R R=0.81$ (Table 3); this appears to deviate from the otherwise monotonic trend of decreasing RR associated with tamoxifen treatment, with increasing AS.

Like others [26], we made a slight modification to our calculation of the AS for individuals carrying two IM (i.e., reduced activity) alleles, where we provided a distinction between individuals classified as $\mathrm{EM} / \mathrm{PM}(\mathrm{AS}=1)$, $\mathrm{IM} / \mathrm{IM}(\mathrm{AS}=0.75)$, and IM/PM (AS = 0.5). Coding the AS this way allowed us to distinguish between different IM diplotypes, which have been shown to have variable levels of enzyme activity [36]. In particular, there is some evidence that $C Y P 2 D 6 * 10$, a reduced activity allele, may have activity that is closer to 0 than 1 [9]. These categories were then combined in the overall phenotype analysis.

Both randomized controlled clinical trials $[3,40]$ and observational studies [41-43], including those from our group $[5,6,44]$, have found a protective effect of tamoxifen with respect to risk of $\mathrm{CBC}$. Some studies have found that this effect is limited to women diagnosed with ER-positive breast cancer [40], while others have not $[5,6,41]$. We have previously reported that tamoxifen treatment was associated with approximately a $27 \%$ lower risk of $\mathrm{CBC}$, with no evidence that the association differed by ER status of the first primary breast cancer [6].

In our study, a relatively large proportion (41\%) of women with ER-positive first breast cancers did not receive hormonal therapy of any kind, while some women with ER-negative breast cancer did (18\%). This may have happened because approximately $20 \%$ of women included in this study were diagnosed with a first primary breast cancer prior to 1989 (Table 1), a time when tamoxifen was given as a treatment regardless of ER status. Notably, just as tamoxifen is used as a chemopreventive agent in women at high risk of developing a first breast cancer (e.g., BRCA mutation carriers) [45], tamoxifen treatment for a first breast cancer can be seen to serve two functions; first, to treat the diagnosed cancer; and second, to prevent a second, independent breast cancer (i.e., $\mathrm{CBC}$ ).

A major and unique strength of this study is our ability to investigate the impact of the CYP2D6 phenotype specifically on the risk of $\mathrm{CBC}$. This was made possible given our use of a retrospective, multicenter, population-based design, which allowed for the inclusion of a large number of women diagnosed with CBC. Another key strength was the availability of detailed treatment histories from medical records, including both tamoxifen treatment as well as other treatments that were included as covariates in the analysis. This study also has some limitations. Information regarding use of other medications (beyond those used for treatment of a first breast cancer) was not collected. Consequently, we were not able to account for drugs that have been observed to inhibit CYP2D6 (e.g., SSRIs), although evidence to date suggests that any possible effects are likely quite modest [46]. We also had no information on CYP2D6 copy number variation and therefore were not able to identify ultra-rapid metabolizers within our study population. In addition, the WECARE Study predominantly consists of Caucasian women, limiting the generalizability of our results somewhat. However, although the CYP2D6 variant frequency and corresponding inferred phenotypes have been shown to vary by race/ ethnicity [47], their impact on metabolite concentration does not [26].

Aromatase inhibitors are now the first-line hormonal treatment for postmenopausal women with ER-positive breast cancer [48], while tamoxifen treatment remains the first-choice treatment for premenopausal women. Our study includes women who were younger than 55 years of age at the time of first diagnosis, so that the majority ( $75 \%$ ) of study participants were premenopausal at the time of first breast cancer diagnosis and treatment. Thus, these results are generalizable to women who are most likely to be prescribed tamoxifen under current standards of care. With a more precise identification of women in whom tamoxifen treatment is unlikely to effectively reduce their risk of $\mathrm{CBC}$, alternative therapies can then be offered (e.g., ovarian oblation plus aromatase inhibitors in premenopausal women) [49]. This would be particularly important for women known to be at an increased risk of $\mathrm{CBC}$ (e.g., women with a family history of $\mathrm{CBC}$ ) [50]. Since our findings suggest that CYP2D6 phenotype may impact the effectiveness of tamoxifen for prevention of second primary breast cancers, it may also be relevant with regards to the use of tamoxifen as a chemopreventive agent among high-risk women. To our knowledge only a single study has examined the impact of the CYP2D6 phenotype on breast cancer prevention with tamoxifen, and no association between the CYP2D6 phenotype and ER-positive breast cancer occurrence was observed [51].

\section{Conclusions}

Women frequently overestimate their risk of $\mathrm{CBC}$, leading to increasing rates of contralateral prophylactic mastectomy. Overall, this study provides early evidence that the CYP2D6 phenotype may contribute to some of the observed variability in the impact of tamoxifen treatment for a first breast cancer on the risk of developing $\mathrm{CBC}$. Identifying factors that can influence a woman's risk of developing $\mathrm{CBC}$ will inform discussions between patient and physician, help guide treatment decisions, and strengthen evidence-based risk communication.

\section{Additional files}

Additional file 1: CYP2D6 polymorphisms tested, primer sequences, and PCR conditions for genotyping. (XLSX $10 \mathrm{~kb}$ ) 
Additional file 2: CYP2D6 variant details by case-control status. (DOCX $27 \mathrm{~kb}$ )

Additional file 3: Association between tamoxifen treatment and risk of CBC stratified by CYP2D6 activity score in women with ER-positive first breast cancer in the WECARE Study population. (DOCX $16 \mathrm{~kb}$ )

Additional file 4: Association between tamoxifen treatment and risk of CBC stratified by CYP2D6 activity score in women who are premenopausal at first diagnosis in the WECARE Study population. (DOCX $17 \mathrm{~kb}$ )

Additional file 5: Association between tamoxifen treatment and risk of CBC stratified by CYP2D6 activity score in Caucasian women in the WECARE Study population (DOCX $16 \mathrm{~kb}$ )

\section{Abbreviations}

AS: Activity score; CBC: Contralateral breast cancer; Cl: Confidence interval: EM: Extensive metabolizer; ER: Estrogen receptor; HWE: Hardy-Weinberg equilibrium; IM: Intermediate metabolizer; MAF: Minor allele frequency; PM: Poor metabolizer; QC: Quality control; RR: Rate ratio; SEER: Surveillance Epidemiology and End Results; SNP: Single nucleotide polymorphism; UBC: Unilateral breast cancer; WECARE: Women's Environmental Cancer and Radiation Epidemiology

\section{Acknowledgements}

The authors would like to thank the WECARE Study participants. The Women's Environmental, Cancer and Epidemiology (WECARE) Study Collaborative Group includes: Memorial Sloan Kettering Cancer Center (Coordinating Center) investigators and staff-Jonine L. Bernstein PhD (WECARE Study P.I.); Marinela Capanu PhD; Xiaolin Liang MD; Irene Orlow MSc, PhD; Anne S. Reiner MPH; Mark Robson, MD; and Meghan Woods MPH; collaborative site investigators—Leslie Bernstein PhD; John D. Boice Jr. ScD; Jennifer D. Brooks PhD; Patrick Concannon PhD; Dave V. Conti PhD; David Duggan PhD; Joanne W. Elena PhD, MPH; Robert W. Haile DrPH; Esther M. John PhD; Julia A. Knight PhD; Charles F. Lynch MD, PhD; Kathleen E. Malone PhD; Lene Mellemkjær PhD; Jørgen H. Olsen MD DMSc; Daniela Seminara PhD MPH; Roy E. Shore PhD, DrPH; Marilyn Stovall PhD; Daniel O. Stram PhD; Marc Tischkowitz MD, PhD; and Duncan C. Thomas PhD; and collaborative site staff-Kristina Blackmore MSc; Anh T. Diep; Judy Goldstein; Irene Harris BS, CMD; Rikke Langballe MPH; Cecilia O'Brien; Susan Smith MPH; Rita Weathers MS; and Michele West PhD.

\section{Funding}

This research was supported by the US National Institutes of Health. This work was supported by the National Institutes of Health (grant no. CA129639, CA083178, CA097397, CA114236, and P30 CA008748) as well as the Chanel Endowment to Fund Survivorship Research. The funding body had no role in the design of the study, in the collection, analysis, and interpretation of the data, or in writing the manuscript.

\section{Availability of data and materials}

The datasets used in the current study are available upon application to the WECARE Study (Principal Investigator: Jonine Bernstein).

\section{Authors' contributions}

$J D B$, JLB, and KEM contributed to the conception and design of the study. 10 contributed to the assay design. JDB, XL, LM, JAK, CFL, EMJ, LB, MW, JLB, IO, SFL, and KEM contributed to data acquisition. JDB, KEM, ASR, DRD, and XL contributed to data analysis. All authors contributed to the interpretation of the results. JDB drafted the initial manuscript and all authors contributed to the intellectual content of the revisions. EAC contributed to the conception and design of the study. All authors approved the final version of the manuscript.

\section{Ethics approval and consent to participate}

All study participants provided written informed consent, and the study was approved by local Institutional Review Boards or Research Ethics Boards.

\section{Consent for publication}

Not applicable.

\section{Competing interests}

The authors declare that they have no competing interests.

\section{Publisher's Note}

Springer Nature remains neutral with regard to jurisdictional claims in published maps and institutional affiliations.

\section{Author details}

${ }^{1}$ University of Toronto, Dalla Lana School of Public Health Sciences, 155 College St. HSB 676, Toronto, ON M5T 3M7, Canada. ${ }^{2}$ Memorial Sloan Kettering Cancer Center, New York, NY, USA. ${ }^{3}$ Danish Cancer Society Research Center, Copenhagen, Denmark. ${ }^{4}$ Lunenfeld-Tanenbaum Research Institute, Sinai Health System, Toronto, Canada. ${ }^{5}$ University of lowa, lowa City, IA, USA. ${ }^{6}$ Department of Medicine and Stanford Cancer Institute, Stanford University School of Medicine, Stanford, CA, USA. ${ }^{7}$ Beckman Research Institute, City of Hope National Medical Centre, Duarte, CA, USA. ${ }^{8}$ Fred Hutchinson Cancer Research Center, Seattle, WA, USA.

Received: 14 May 2018 Accepted: 19 November 2018

Published online: 10 December 2018

\section{References}

1. American Cancer Society. Breast Cancer Facts \& Figures 2015-2016. Atlanta: American Cancer Society, Inc. 2015.

2. Curtis RE, Ron E, Hankey BF, Hoover RN. Chapter 7: New malignancies following breast cancer. In: Curtis RE, Freedman DM, Ron E, LAG R, Hacker DG, Edwards BK, Tucker MA, Jr. FJ, editors. New malignancies among cancer survivors: SEER Cancer Registries, 1973-2000. Bethesda: National Cancer Institute; 2006. p. 181-205.

3. Rutqvist LE, Johansson H, Signomklao T, Johansson U, Fornander T, Wilking N. Adjuvant tamoxifen therapy for early stage breast cancer and second primary malignancies. J Natl Cancer Inst. 1995;87(9):645-51.

4. Early Breast Cancer Trialists' Collaborative Group. Effects of chemotherapy and hormonal therapy for early breast cancer on recurrence and 15-year survival: an overview of the randomised trials. Lancet. 2005;365(9472):1687-717.

5. Bertelsen L, Bernstein L, Olsen JH, Mellemkjaer L, Haile RW, Lynch CF, Malone KE, Anton-Culver H, Christensen J, Langholz B, et al. Effect of systemic adjuvant treatment on risk for contralateral breast cancer in the Women's Environment, Cancer and Radiation Epidemiology Study. J Natl Cancer Inst. 2008;100(1):32-40.

6. Langballe R, Mellemkjær L, Malone KE, Lynch CF, John E, Knight JA, Bernstein L, Brooks JD, Andersson M, Reiner A, et al. Systemic therapy for breast cancer and risk of subsequent contralateral breast cancer in the WECARE Study. Breast Cancer Res. 2016;18(1):65-77.

7. Furr BJA, Jordan VC. The pharmacology and clinical uses of tamoxifen. Pharmacol Ther. 1984;25(2):127-205.

8. Lim YC, Desta Z, Flockhart DA, Skaar TC. Endoxifen (4-hydroxy-N-desmethyltamoxifen) has anti-estrogenic effects in breast cancer cells with potency similar to 4-hydroxy-tamoxifen. Cancer Chemother Pharmacol. 2005:55(5):471-8.

9. Goetz MP, Sangkuhl K, Guchelaar H-J, Schwab M, Province M, Whirl-Carrillo M, Symmans WF, McLeod HL, Ratain MJ, Zembutsu H, et al. Clinical Pharmacogenetics Implementation Consortium (CPIC) Guideline for CYP2D6 and Tamoxifen Therapy. Clin Pharmacol Ther. 2018;103(5):770-7. https:/doi.org/10. 1002/cpt.1007.

10. Schroth W, Antoniadou L, Fritz P, Schwab M, Muerdter T, Zanger UM, Simon W, Eichelbaum M, Brauch H. Breast cancer treatment outcome with adjuvant tamoxifen relative to patient CYP2D6 and CYP2C19 genotypes. J Clin Oncol. 2007;25(33):5187-93.

11. Goetz M, Knox S, Suman V, Rae J, Safgren S, Ames M, Visscher D, Reynolds C, Couch F, Lingle W, et al. The impact of cytochrome P450 2D6 metabolism in women receiving adjuvant tamoxifen. Breast Cancer Res Treat. 2007;101(1):113-21.

12. Lim H-S, Ju Lee H, Seok Lee K, Sook Lee E, Jang I-J, Ro J. Clinical implications of CYP2D6 genotypes predictive of tamoxifen pharmacokinetics in metastatic breast cancer. J Clin Oncol. 2007;25(25): 3837-45.

13. Bonanni B, Macis D, Maisonneuve P, Johansson HA, Gucciardo G, Oliviero P, Travaglini R, Muraca MG, Rotmensz N, Veronesi U, et al. Polymorphism in the CYP2D6 tamoxifen-metabolizing gene influences clinical effect but not hot flashes: data from the Italian Tamoxifen Trial. J Clin Oncol. 2006;24(22):3708-9. 
14. Bijl $M$, van Schaik R, Lammers $L$, Hofman A, Vulto A, van Gelder T, Stricker B, Visser L. The CYP2D6*4 polymorphism affects breast cancer survival in tamoxifen users. Breast Cancer Res Treat. 2009;118(1):125-30.

15. Thompson A, Johnson A, Quinlan P, Hillman G, Fontecha M, Bray S, Purdie C, Jordan L, Ferraldeschi R, Latif A, et al. Comprehensive CYP2D6 genotype and adherence affect outcome in breast cancer patients treated with tamoxifen monotherapy. Breast Cancer Res Treat. 2011;125(1):279-87.

16. Wegman P, Elingarami S, Carstensen J, Stal O, Nordenskjold B, Wingren S. Genetic variants of CYP3A5, CYP2D6, SULT1A1, UGT2B15 and tamoxifen response in postmenopausal patients with breast cancer. Breast Cancer Res. 2007;9(1):R7.

17. Wegman P, Vainikka L, Stal O, Nordenskjold B, Skoog L, Rutqvist L-E, Wingren S. Genotype of metabolic enzymes and the benefit of tamoxifen in postmenopausal breast cancer patients. Breast Cancer Res. 2005;7(3):R284-90.

18. Abraham J, Maranian M, Driver K, Platte R, Kalmyrzaev B, Baynes C, Luccarini C, Shah M, Ingle S, Greenberg D, et al. CYP2D6 gene variants: association with breast cancer specific survival in a cohort of breast cancer patients from the United Kingdom treated with adjuvant tamoxifen. Breast Cancer Res. 2010;12(4):R64.

19. Lash TL, Cronin-Fenton D, Ahern TP, Rosenberg CL, Lunetta KL, Silliman RA, Garne JP, Sørensen HT, Hellberg Y, Christensen M, et al. CYP2D6 inhibition and breast cancer recurrence in a population-based study in Denmark. J Natl Cancer Inst. 2011;103(6):489-500.

20. Nowell SA, Ahn J, Rae JM, Scheys JO, Trovato A, Sweeney C, MacLeod SL, Kadlubar FF, Ambrosone CB. Association of genetic variation in tamoxifenmetabolizing enzymes with overall survival and recurrence of disease in breast cancer patients. Breast Cancer Res Treat. 2005;91(3):249-58.

21. Rae JM, Drury S, Hayes DF, Stearns V, Thibert JN, Haynes BP, Salter J, Sestak I, Cuzick J, Dowsett M. CYP2D6 and UGT2B7 genotype and risk of recurrence in tamoxifen-treated breast cancer patients. J Natl Cancer Inst. 2012;104(6):452-60.

22. Regan MM, Leyland-Jones B, Bouzyk M, Pagani O, Tang W, Kammler R, Dell'Orto P, Biasi MO, Thürlimann B, Lyng MB, et al. CYP2D6 genotype and tamoxifen response in postmenopausal women with endocrine-responsive breast cancer: the Breast International Group 1-98 trial. J Natl Cancer Inst. 2012;104(6):441-51.

23. Pharoah PDP, Abraham J, Caldas C. Re: CYP2D6 genotype and tamoxifen response in postmenopausal women with endocrine-responsive breast cancer: the Breast International Group 1-98 trial and Re: CYP2D6 and UGT2B7 genotype and risk of recurrence in tamoxifen-treated breast cancer patients. J Natl Cancer Inst. 2012;104(16):1263-4.

24. Stanton V. Re: CYP2D6 genotype and tamoxifen response in postmenopausal women with endocrine-responsive breast cancer: the Breast International Group 1-98 trial. J Natl Cancer Inst. 2012;104(16):1265-6.

25. Nakamura Y, Ratain MJ, Cox NJ, Mcleod HL, Kroetz DL, Flockhart DA. Re: CYP2D6 genotype and tamoxifen response in postmenopausal women with endocrine-responsive breast cancer: the Breast International Group 1-98 trial. J Natl Cancer Inst. 2012;104(16):1264.

26. Saladores $P$, Murdter T, Eccles D, Chowbay B, Zgheib NK, Winter S, Ganchev B, Eccles B, Gerty S, Tfayli A, et al. Tamoxifen metabolism predicts drug concentrations and outcome in premenopausal patients with early breast cancer. Pharmacogenomics J. 2015;15(1):84-94.

27. Hertz DL, Kidwell KM, Hilsenbeck SG, Oesterreich S, Osborne CK, Philips S, Chenault C, Hartmaier RJ, Skaar TC, Sikora MJ, et al. CYP2D6 genotype is not associated with survival in breast cancer patients treated with tamoxifen: results from a population-based study. Breast Cancer Res Treat. 2017;166(1):277-87.

28. Brooks JD, John EM, Mellemkjær L, Lynch CF, Knight JA, Malone KE, Reiner AS, Bernstein L, Liang $X$, Shore RE, et al. Body mass index, weight change, and risk of second primary breast cancer in the WECARE study: influence of estrogen receptor status of the first breast cancer. Cancer Med. 2016;5(11):3282-91.

29. Bernstein J, Langholz B, Haile R, Bernstein L, Thomas D, Stovall M, Malone K, Lynch C, Olsen J, Anton-Culver H, et al. Study design: Evaluating geneenvironment interactions in the etiology of breast cancer-the WECARE study. Breast Cancer Res. 2004;6(3):R199-214.

30. Dean L. In: MH PV, Dean L, et al., editors. Tamoxifen therapy and CYP2D6 genotype. Bethesda: National Center for Biotechnology Information (US); 2014. [updated 2016 May 3].

31. Falzoi M, Pira L, Lazzari P, Pani L. Genotyping of CYP2D6 polymorphisms by MALDI-TOF mass spectrometry in Sardinian people. ISRN Genetics. 2013; 2013:1-10.
32. Orlow I, Roy P, Reiner AS, Yoo S, Patel H, Paine S, Armstrong BK, Kricker A, Marrett LD, Millikan RC, et al. Vitamin D receptor polymorphisms in patients with cutaneous melanoma. Int J Cancer. 2012;130(2):405-18.

33. Correa DD, Satagopan J, Cheung $K$, Arora AK, Kryza-Lacombe M, Xu Y, Karimi S, Lyo J, DeAngelis LM, Orlow I. COMT, BDNF, and DTNBP1 polymorphisms and cognitive functions in patients with brain tumors. Neuro-Oncology. 2016;18(10):1425-33.

34. Okubo M, Murayama N, Miura J, Shimizu M, Yamazaki H. A rapid multiplex PCR assay that can reliably discriminate the cytochrome P450 2D6 whole-gene deletion allele from 2D6*10 alleles. Clin Chim Acta. 2012;413(19):1675-7.

35. Lyon E, Gastier Foster J, Palomaki GE, Pratt VM, Reynolds K, Sabato MF, Scott SA, Vitazka P. Laboratory testing of CYP2D6 alleles in relation to tamoxifen therapy. Genet Med. 2012;14(12):990-1000.

36. Hertz DL, Snavely AC, McLeod HL, Walko CM, Ibrahim JG, Anderson S, Weck KE, Magrinat G, Olajide O, Moore S, et al. In vivo assessment of the metabolic activity of CYP2D6 diplotypes and alleles. Br J Clin Pharmacol. 2015;80(5):1122-30

37. Zineh I, Beitelshees AL, Gaedigk A, Walker JR, Pauly DF, Eberst K, Leeder JS, Phillips MS, Gelfand CA, Johnson JA. Pharmacokinetics and CYP2D6 genotypes do not predict metoprolol adverse events or efficacy in hypertension. Clin Pharmacol Ther. 2004;76(6):536-44.

38. Province MA, Goetz MP, Brauch H, Flockhart DA, Hebert JM, Whaley R, Suman VJ, Schroth W, Winter S, Zembutsu H, et al. CYP2D6 genotype and adjuvant tamoxifen: meta-analysis of heterogeneous study populations. Clin Pharmacol Ther. 2014;95(2):216-27.

39. Harris LN, Ismaila N, McShane LM, Andre F, Collyar DE, Gonzalez-Angulo AM, Hammond EH, Kuderer NM, Liu MC, Mennel RG, et al. Use of biomarkers to guide decisions on adjuvant systemic therapy for women with early-stage invasive breast cancer: American Society of Clinical Oncology Clinical Practice Guideline. J Clin Oncol. 2016;34(10):1134-50.

40. Early Breast Cancer Trialists' Collaborative Group. Relevance of breast cancer hormone receptors and other factors to the efficacy of adjuvant tamoxifen: patient-level meta-analysis of randomised trials. Lancet. 2011; 378(9793):771-84.

41. Phillips K-A, Milne RL, Rookus MA, Daly MB, Antoniou AC, Peock S, Frost D, Easton DF, Ellis S, Friedlander ML, et al. Tamoxifen and risk of contralateral breast cancer for BRCA1 and BRCA2 mutation carriers. J Clin Oncol. 2013; 31(25):3091-9.

42. Cook LS, Weiss NS, Schwartz SM, White E, McKnight B, Moore DE, Daling JR. Population-based study of tamoxifen therapy and subsequent ovarian, endometrial, and breast cancers. J Natl Cancer Inst. 1995;87(18): 1359-64.

43. Schaapveld M, Visser O, Louwman WJ, Willemse PHB, de Vries EGE, van der Graaf WTA, Otter R, JCoebergh aWW, van Leeuwen FE. The impact of adjuvant therapy on contralateral breast cancer risk and the prognostic significance of contralateral breast cancer: a population based study in the Netherlands. Breast Cancer Res Treat. 2008;110(1):189-97.

44. Mellemkjær L, Steding-Jessen M, Frederiksen K, Andersson M, Ejlertsen B, Jensen M-B, Olsen JH. Risk of contralateral breast cancer after tamoxifen use among Danish women. Ann Epidemiol. 2014;24(11):843-8.

45. Cuzick J, Sestak I, Bonanni B, Costantino JP, Cummings S, DeCensi A, Dowsett M, Forbes JF, Ford L, LaCroix AZ, et al. Selective oestrogen receptor modulators in prevention of breast cancer: an updated meta-analysis of individual participant data. Lancet. 2013;381(9880):1827-34.

46. Cronin-Fenton DP, Lash TL. Clinical epidemiology and pharmacology of CYP2D6 inhibition related to breast cancer outcomes. Expert Rev Clin Pharmacol. 2011;4(3):363-77.

47. Sistonen J, Sajantila A, Lao O, Corander J, Barbujani G, Fuselli S. CYP2D6 worldwide genetic variation shows high frequency of altered activity variants and no continental structure. Pharmacogenet Genomics. 2007; 17(2):93-101.

48. Goss PE, Ingle JN, Pritchard KI, Robert NJ, Muss H, Gralow J, Gelmon K, Whelan T, Strasser-Weippl K, Rubin S, et al. Extending aromatase-inhibitor adjuvant therapy to 10 years. N Engl J Med. 2016;375(3):209-19.

49. Pagani O, Regan MM, Walley BA, Fleming GF, Colleoni M, Láng I, Gomez HL, Tondini C, Burstein HJ, Perez EA, et al. Adjuvant exemestane with ovarian suppression in premenopausal breast cancer. New Engl J Med. 2014; 371(2):107-18.

50. Reiner A, John E, Brooks J, Lynch C, Bernstein L, Mellemkjær L, Malone K, Knight J, Capanu M, Teraoka S, et al. Risk of asynchronous contralateral breast cancer in non-carriers of BRCA1 and BRCA2 mutations with a family 
history of breast cancer: a report from the WECARE Study. J Clin Oncol. 2013;31(4):433-9.

51. Sestak I, Kealy R, Nikoloff M, Fontecha M, Forbes JF, Howell A, Cuzick J. Relationships between CYP2D6 phenotype, breast cancer and hot flushes in women at high risk of breast cancer receiving prophylactic tamoxifen: results from the IBIS-I trial. Br J Cancer. 2012. https://doi.org/10.1038/bjc.2012.278.

Ready to submit your research? Choose BMC and benefit from:

- fast, convenient online submission

- thorough peer review by experienced researchers in your field

- rapid publication on acceptance

- support for research data, including large and complex data types

- gold Open Access which fosters wider collaboration and increased citations

- maximum visibility for your research: over $100 \mathrm{M}$ website views per year

At $\mathrm{BMC}$, research is always in progress.

Learn more biomedcentral.com/submissions 